\title{
Reseña de Ovejero y Ramos (2011) Psicología social crítica Review of Ovejero y Ramos (2011) Psicología social crítica
}

\author{
Pamela Vaccari Jiménez \\ Universitat de Girona \\ Marco Astete Cereceda \\ Universitat Autònoma de Barcelona
}

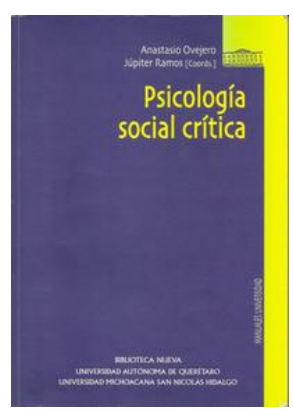

Una de las primeras preguntas que podrían surgir en el encuentro con este libro es ¿A que nos estamos refiriendo cuando hablamos de una psicología social crítica?. Entendiendo que, "la psicología no puede ser otra cosa que psicología social" (Eberle, 1993, p.1, citado por Ovejero, 2011, en Ovejero y Ramos, 2011, pág, 25.), nos planteamos: ¿Qué hace distintiva la psicología social crítica de la que hemos asumido comúnmente?

Porque querámoslo o no, hablamos mucho de psicología, casi de forma indeliberada, lo que muestra como ésta ha ido acaparando paulatinamente todos los espacios de nuestra vida cotidiana. Sólo hay que percatarse de lo habitual que resulta opinar de estrés, déficit atencional o inteligencia emocional. ¿Y qué implicancias tiene esto?, pues bastantes... sin embargo, lo primero es constatar que justa-
Ovejero, Anastasio y Ramos, Júpiter (2011) Psicología social crítica. Madrid: Biblioteca Nueva.

ISBN: 978-84-9940-202-4 mente, éste es uno de los temas clave que interesan a la psicología social crítica: la psicologización de lo social, en especial cuando ha venido operando de forma maquinal y naturalizada, con pretensiones de controlar, regular, diagnosticar y prescribir lo que somos y debiéramos ser.

A la corriente crítica le preocupa la psicologización de lo social, en el sentido de que existirían una suerte de sobre diagnósticos para analizar nuestro entorno y ello ha venido despertando algunas sospechas, tales como iA quién o quienes les interesa que como sociedad asumamos tantas y más explicaciones sobre nuestra forma de ser y estar en el mundo?

Precisamente en este libro, encontraremos pistas sobre las motivaciones de una psicología social crítica y también muchas preguntas 
que se articulan como reflexión y autocrítica de las prácticas psicológicas más tradicionales. Las autoras y autores que aquí se presentan, son parte de un proceso crítico que tiene su origen en la mitad de siglo XX, en contrarespuesta una psicología que adquiría cada vez mayor poder y autoridad en el funcionamiento de nuestra sociedad.

¿Y cómo es que fueron gestándose esta serie de cuestionamientos alrededor de la psicología? Es lo que podremos ver en el primer capítulo del libro a cargo de Ovejero (2011, en Ovejero y Ramos, 2011, pág, 25) donde se recorren algunos hitos en la historia de la psicología social, cómo por ejemplo, su validación en occidente como disciplina experta en lo mental.

Esta es la misma psicología, que en la actualidad se asume como verdad y realidad (Ibáñez, 2005, en Ovejero y Ramos, 2011, p. 274), heredera del paradigma ilustrado y de la filosofía positivista; la misma que afirma que las personas tenemos o debiéramos tener, una condición definida y estable en cuanto a comportamiento y emociones; la misma que trabaja reduciendo y cuantificando variables, creyendo que sólo así podemos llegar a la comprensión de lo psicosocial. Es la psicología que logra ser hegemónica y que se valida ampliamente como "una nueva disciplina capaz de analizar y mantener el orden social en el plano individual" (Parker, 2010, p. 23, citado por Ovejero, 2011, en Ovejero y Ramos, 2011, p.25).

En oposición a lo anterior, la psicología social crítica canaliza las objeciones y preguntas de quienes se resisten a asumir esta forma de hacer psicología. Puede verse de esta manera, como un movimiento y un sitio desde donde observar con suspicacia todas nuestras prácticas sociales y todo lo que se dice sobre ellas desde el orden dominante. En el libro Psicología social crítica de Ovejero y Ramos (2011) hallamos por tanto a distintos grados y niveles, este espíritu de contracorriente y de disidencia frente a la psicología más clásica, tradicional que se asume como verdad y realidad sobre cómo somos las personas y las sociedades.

$Y$ es que las autoras y autores de este compilado, implícitamente se preguntan: ¿acaso existe un único patrón de ser y estar? claramente decimos que no... y he aquí la invita- ción para seguir leyendo, podemos ¿indagar?, ¿construir?, ¿proponer?... cualquiera sea la opción que ustedes descubran en estas páginas, lo importante será que su inspiración, la psicología social crítica, reconoce que existen múltiples formas de hacer y crear en el mundo.

No obstante para la psicología tradicional o mainstream, este debate no se admite. Desde su posición de autoridad rechaza estos planteamientos. Atribuye a quienes critican su filosofía y métodos, falta de objetividad y exceso de ideología. Pero acaso, ¿Hay algo más ideológico que pensar sólo una forma válida de hacer ciencia?, ¿Hay algo menos ideológico que una aproximación psicológica a los problemas sociales? Creemos rotundamente que no.

Por esta razón, aunque la psicología mainstream se refiera a sí misma como neutra, para la psicología social crítica, estos supuestos de neutralidad no hacen más que servir al poder y orden dominantes. Porque si esto no es así, ¿Cómo se explica por ejemplo que en el área de estudios sobre la influencia, la psicología históricamente haya estudiado los rasgos de sumisión y conformismo, y no los de independencia y rebeldía? (Ovejero y Ramos, 2011, en Ovejero y Ramos, 2011, p. 19).

Junto al libro Psicología social crítica, podemos empezar a preguntarnos entonces (si es que aún no lo habíamos hecho) ¿Dónde estamos como disciplina en relación con la sociedad? ¿cuáles son las ideologías que legitiman nuestro actual sistema y status quo? Muchos indicios se nos señalan aquí, porque como dicen Ovejero y Ramos (2011) la psicología social crítica tiene una motivación clara para ir a desenmascarar, los intereses y fines que se esconden tras ciertas prácticas profesionales que sirven al poder. Para ello es necesario "establecer los dispositivos que permitan a la psicología ponerse al servicio de la resistencia a la dominación" (Ovejero y Ramos, 2011, en Ovejero y Ramos, 2011 p. 14).

El lenguaje es un elemento de análisis crucial para la psicología social crítica, pues le considera como una herramienta capaz de crear y regular el espacio social, donde las prácticas lingüísticas son acciones que mantienen y promueven ciertas relaciones sociales (Íñiguez y Antaki, 1994; citado por Íñiguez, Martínez y Pons, 2011, en Ovejero y Ramos, 2011, 
pág.103). Y aquí la psicología social crítica se aleja definitivamente de la psicología mainstream, porque asume que la realidad es construida socialmente, es decir, que no es independiente de la forma en que la abordamos con nuestra historia y contexto social. La comprensión del discurso en estos sentidos, permite tener una herramienta para la transformación social y la psicología social crítica, se plantea transformar las cosas más allá del status quo y del orden dominante.

Esto es lo que tensionan las autoras y autores de este libro, cuyas páginas nos llevan a reflexionar sobre la esencia del poder hegemónico actual, que sigue unas lógicas de control y producción específicos. Sobre ella, la psicología social crítica identifica la base de la desigualdad entre personas, países y grupos sociales, lo cual es en definitiva, el modus operandis del capitalismo que gobierna gran parte del funcionamiento social global, ya casi tan naturalizado como la psicologización de lo cotidiano.

$Y$ no es casualidad que sean momentos de coherencia entre estas formas de mirar el mundo, capitalismo y psicologización...en el libro Psicología social crítica se nos señala que tradicionalmente la psicología ha contribuído al poder como herramienta de control social, psicologizando los problemas sociales para que las personas se fijen en sí mismas como auténticas responsables de lo que les sucede (Ovejero y Ramos, 2011, p. 17) y nunca en analizar por ejemplo, las estrategias del poder para validar algunas opciones (las que más le sirven) en desmedro de otras (las que podrían cuestionarle). Esto anula toda posibilidad de articulación social que podría hacer mella en el actual sistema. Inclusive cuando existen personas que no pueden ser tan dóciles ni receptivas con los requerimientos de la psicología mainstream, antes de que éstas puedan hacer algo, se les aísla y señala como fuera de lo aceptable, de este modo, la organización social se ve debilitada, reforzándose además la idea (en términos negativos), de que quienes no se adaptan, son apartados/as del sistema.

Una contribución tácita de este libro es por tanto, ilustrar que los preceptos de una psicología social de verdades universales sólo sirve para mantener situaciones de desigualdad. Por ello el trabajo de resistencia de la psicología social crítica es fundamental para con- vocar reflexiones y acciones que se motiven por desarrollar algo diferente de lo que el sistema impone.

Algunos de esos aportes y reflexiones alternativas son las que podremos ver en este libro, entre ellas, las de los estudios feministas al desarrollo de la ciencia social crítica (Cabruja y Fernández-Villanueva, 2011, en Ovejero y Ramos, 2011), la investigación psicológica como construcción social (Gergen y Gergen, 2011, en Ovejero y Ramos, 2011), y los estudios del discurso (Íñiguez, Martínez y Pons, 2011; Potter y Hepburn, 2011, todos en Ovejero y Ramos, 2011). Desarrollos críticos que a su vez interpelan problemáticas tan diversas como por ejemplo, las políticas públicas en salud (Navarro y Meza, 2011en Ovejero y Ramos, 2011) o la vida cotidiana (Maldonado y Carrillo, 2011, en Ovejero y Ramos, 2011).

En relación a estos trabajos y al modo de hacer ciencia de la psicología social crítica, Tomás Ibáñez (2005, en Ovejero y Ramos 2011, p. 275) en su apreciación va más lejos y nos pregunta: “...pero ¿Para qué conocer?”...y la respuesta crítica obviamente no es para acumular saberes, porque este debate hay que comprenderlo lejos de los modelos tradicionales de hacer ciencia, donde no cabe la noción clásica de acumular cuantitativamente una serie de estudios.

Ibáñez (2005, en Ovejero y Ramos, 2011, p. 275) nos recuerda entonces, que para hacer ciencia crítica es necesario entender que el conocimiento es un fin y no un medio. Cuando hemos logrado comprender esto, la siguiente pregunta ineludible es: "¿para alcanzar que fines?"...y en este punto Ibáñez nos dice que sólo corresponde un debate de nuestros valores, que son finalmente lo único que justifica nuestro trabajo por desarrollar conocimientos psicosociales.

Con estos antecedentes, podemos imaginar entonces que la apuesta de las autoras y autores del libro Psicología social crítica es también de sus valores... personales o colectivos, porque en cada escrito e investigación, van asumiendo posiciones respecto de las realidades que analizan y de acuerdo con Ibáñez (2005, en Ovejero y Ramos 2011, p. 276) esto indudablemente dejará huellas en los conocimientos que trabajan.

¿Esta forma de investigar dotará de mayor compromiso a quienes se involucran en una 
psicología social que no quiere favorecer el status quo?, creemos decididamente que sí, por lo menos hay un interés porque sus saberes no sean utilizados para el control social, sino para la apertura de espacios con más debates y menos hegemonías. La psicología social crítica es una forma de resistencia a toda intención de poder totalitario y sus estudios buscan por tanto subvertir y cuestionar cualquier funcionamiento de la sociedad que sea dominante y excluyente. En esta misma línea ustedes se encontrarán con una heterogeneidad de análisis en esta recopilación de trabajos, cuyo hilo crítico, va marcando las excepciones e invisibilidades que muchas veces no tienen cabida en una psicología que mantiene y defiende las cosas tal y como se han hecho tradicionalmente.

La invitación que nos ofrece este libro por tanto es a hacernos preguntas sobre las sociedades y personas que queremos ser, y asumir como dice Ibáñez (2005, en Ovejero y Ramos, 2011), que todo nuestro quehacer está motivado y producido en nuestra cotidianeidad y contingencia, y...que es posible construir otros mundos fuera de las formas establecidas, (lo que el ejemplifica como un mundo sin iglesias) atendiendo a que desde el momento en que la psicología social crítica asuma una forma de iglesia, será necesario remecer inmediatamente los cimientos de ese nuevo poder hegemónico.

\section{PAMela VACCARI JIMÉNeZ}

Estudiante Doctorado en Psicología Social. Universidad Autónoma de Barcelona. Integrante grupo de investigación DIGECIC (Discurso, Género, Ciencia y Cultura, perteneciente al Instituto de Investigación sobre Calidad de Vida de la Universidad de Girona (IRQV) y del Instituto Interuniversitario de Estudios de Mujeres y Género, IIEDG).

\section{MARCo Astete Cereceda}

Estudiante Doctorado en Psicología Social. Universidad Autónoma de Barcelona.

\section{DIRECCIÓN DE CONTACTO}

pamela.vaccari@gmail.com

marcoastete@yahoo.com

\section{FORMATO DE CITACIÓN}

Vaccari Jiménez, Pamela y Astete Cereceda, Marco (2011). Reseña de Ovejero y Ramos (2011) Psicología social crítica. Quaderns de Psicologia, 13(2), 77-80. Extraido el [día] de [mes] del [año], de http://www.quadernsdepsicologia.cat/article/view/1056 